EPiC Series in Engineering
Volume 3, 2018, Pages 1616-1623
HIC 2018. 13th International
Conference on Hydroinformatics

\title{
A DSS for operational management of wastewaters under uncertain conditions
}

\author{
A. Pereira ${ }^{1,2}$, J.L.S. Pinho ${ }^{1}$, R. Faria ${ }^{2}$, J.M.P. Vieira ${ }^{1}$ \\ ${ }^{1}$ Centre for Territory, Environment and Construction, Department of Civil Engineering, \\ University of Minho, Campus de Gualtar, 4710-057 Braga, Portugal \\ ${ }^{2}$ TRATAVE, SA, 4765-543 Serzedelo, Guimarães, Portugal \\ antonio.pereira@tratave.pt, jpinho@civil.uminho.pt, \\ rolando.fariadtratave.pt, jvieira@civil.uminho.pt
}

\begin{abstract}
Wastewater treatment facilities of the Ave River basin (located in NW Portugal) are especially vulnerable to infiltration since they present considerable extensions of sewers installed in streams and rivers and collect wastewaters from longstanding sewer networks of five municipalities. The operational management of this complex system involves decision variables such as the selection of the treatment plant where collected wastewater will be treated, with implications for pumped volumes and consequent energy consumption. Aiming to reduce these inflows and increase the management performance of TRATAVE, the company responsible for operating the system, a monitoring network that includes the entire drainage network and treatment facilities operated by the company was designed and implemented. Several flow measurement devices were installed at strategic locations within the sewer network and integrated with a SCADA system responsible for its operation. All measured data was organized in databases. This monitoring platform will support the implementation of a decision support system (DSS) based on a hydrological model of the basin, a hydrodynamic model of the river network and the sewer network. The DSS is being implemented using the Delft-FEWS platform, integrating monitoring data and models. The DSS conceptual framework and the first results of the estimated infiltration volumes are presented.
\end{abstract}

\section{Introduction}

A DSS can be defined as an interactive, flexible and adaptable, technological solution, especially designed to support decision making in complex, poorly structured, management problems, including the assessment of policy measure impacts considering different environmental scenarios. These 
technological solutions, originally developed for financial organizations, have been expanded to its application towards water resources management problems.

Undesirable infiltration in wastewater drainage systems have been studied in several previous works. The processes that contribute to these inflows are diverse, namely their entrance through manholes, infiltrations through sewer pipe joints and clandestine connections of storm waters to the wastewater sewers network. These conditions can lead to problems in the drainage system, such as, streets inundation, failure of pump stations, decrease of the wastewater treatment plants efficiency and increase of untreated wastewater discharges to rivers.

Most of the methodologies applied to combat the problem of undue inflows at a national level (Pereira, Pinho, \& Faria., 2016) involve the application of hydrodynamic models in urban environments, often with registers that are not a proper representation of the real scenario. At an international level (Butler \& Schutze., 2005) (Fletcher, Andrieu, \& Hamel., 2013) (Lowe, Vezzaro, Steen, \& Grum., 2016), there has been an investment in the construction of more advanced and detailed simulation models and the flow process to make it possible to identify the structural properties of the systems that most influence the infiltration process in different meteorological scenarios.

It is increasingly in the national (Pinho \& Vieira., 2014) and international's (Joseph-Duran, Carlos, \& Cembrano, 2014) (Lowe, Vezzaro, Steen, \& Grum., 2016) interest to develop and apply operational management methodologies for water resources.

The meteorological conditions, namely short- and medium-term forecasts through robust models, are of extreme importance for decision-making processes and are increasingly being used at an international level (Lowe, Vezzaro, Steen, \& Grum., 2016) (Butler \& Schutze., 2005) (Fletcher, Andrieu, \& Hamel., 2013) (Joseph-Duran, Carlos, \& Cembrano, 2014) and in constant refinement. Nevertheless, in Portugal, it is an aspect that is still too little explored in drainage systems and, as a corollary, the level of knowledge still lags behind other countries, such as Switzerland, France, Denmark, Sweden, Brazil or the United States. The final product of this work is expected to make an important contribution in this regard.

So, the presented solution is composed of the following main components: water monitoring databases, hydrodynamics and river water quality and sewerage models, and facility reports for the presentation of the output results. The applicability of this hydroinformatic environment tool, in this paper, demonstrates forecast uncertainty and sensitivity of overflow locations in order to reduce combined sewer overflow risk, and will present the main features of a DSS that is being implemented with the use of the Delft-FEWS platform aiming to support operational management of wastewaters transport and treatment facilities in a relatively complex case study: the Ave River (NW Portugal) wastewaters system operated by TRATAVE company (Ave valley wastewaters treatment).

\section{Methods}

\subsection{Study site and model}

The case study wastewater collection and treatment facilities system, SIDVA, (Figure 1) includes $126 \mathrm{~km}$ of sewers and five main wastewater treatment plants (WWTP) which collect and treat the industrial (40\% of the influence of the total flow, equivalent to about 40 millions of $\mathrm{m} 3$ per year) and domestic (60\% of the influence of the total flow) effluent from five municipalities: Guimarães, Vizela, Famalicão, Santo Tirso and Trofa. Its components are predominately located on the banks of the Ave River and the tributary valleys, and on a representative part of river bed.

The Ave River's basin consists of a dense network of water lines bounded north by the Cávado River basin, east by the Douro River basin, and south by the Leça River and Douro River basins. The 
Ave basin has a total area of $1469 \mathrm{~km}^{2}$, with $247 \mathrm{~km}^{2}$ and $340 \mathrm{~km}^{2}$ corresponding to the basin areas of the East River and Vizela River's main tributaries, respectively.

In regards to the climate, the region is characterized by very hot and slightly humid summers and cold and rainy winters, presenting annual totals of precipitation reaching $1500 \mathrm{~mm}$. Considering the orographic characteristics of the land, the basins soil constitution, and its permeability, the intense precipitation that occurs during wet periods make this area favorable to flooding. This is why operational management systems with climate forecasts are crucial in minimizing flooding problems.

In fact, this work arose from the need to control undue inflows in order to ensure a better operational performance of the drainage and treatment system, and, as a corollary, to avoid discharges to the rivers.

The DSS system will be based on modelling tools for hydrology, wastewater drainage, rivers, water quality and RTC tools.

The available model implemented at University of Minho, includes the Ave River and its main tributaries: Vilar do Chão River, Castelões River, Pequeno River (left bank of Ave River), Pequeno River (right bank of Ave River), Vizela River, Selho River, Ferro River, Bugio River, Pelhe River, Pele River, Sanguinhedo River, Trofa River, Este River, Macieira River, Tabuaças River and Póvoa River.

In this river model, cross sections were established using bathymetric and topographic available data complemented with SRTM topographic data. The one-dimensional grid is comprised of 1902 computational nodes, 18 open boundaries, 34 controlled discharges at hydraulic structures and 255 noncontrolled hydraulic structures. The Ave River's channel geometry was introduced considering 1936 cross sections.

Pollutant sources are simulated considering 15 different locations within the river basin. All hydraulic structures with a significant influence in the river's flows regime were included with emphasis on weirs and dams.

The segmentation of the model was defined considering the important influence of the upstream reservoirs, the river flows, and the intense occupation (industrial, agriculture and urban areas) of the basin in downstream areas.

The drainage network model works simultaneously with the model of the river. This onedimensional grid is comprised of 2296 computational nodes, 14 open boundaries and 25 measurement stations coincident with the locations of sensor probes installed in the manholes.

The total pipe network length is $126 \mathrm{~km}$ and its geometric characteristics were obtained through topographic fieldworks based on high precision DGPS equipment.

The recently installed sewer pipe monitoring network covers a wide range of sensor probes (unique in the country and rare even at an international level) which measure flow, water level and rainfall at different locations. This comprehensive monitoring data has already allowed the detection and correction of undue inflows, avoiding discharges to rivers and optimizing the energy efficiency of the WWTPs.

Behind the DSS main features that are being implemented, results of estimated infiltrated rain water volumes in the drainage networks during rainy events are presented and discussed. The operational management of this complex system during wet periods involves decision variables, such as the selection of the treatment plant where collected wastewater will be treated with implications for pumped volumes and consequent energy consumption and also detection and minimization of impacts resulting from intense rainfall events that may imply decision on the direct discharge of untreated wastewater into rivers. 


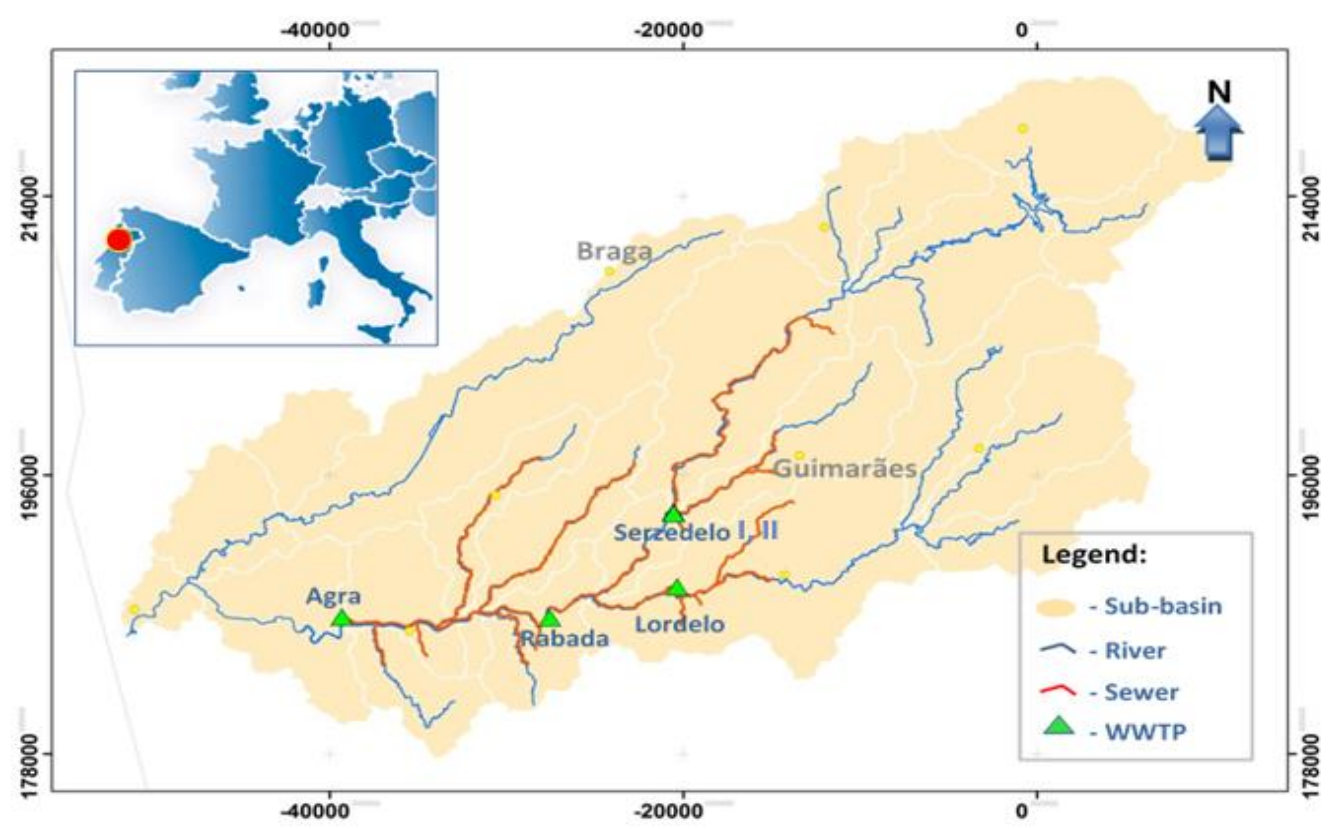

Figure 1 River Ave basin location, main sewer network and WWTP

\subsection{DSS components}

TRATAGESC, running with windows server 2012R2 operating system (Figure 2). A monitoring network was designed and installed to allow for the continuous measurement of wastewater flows at strategic locations along the drainage network, supplemented with four meteorological stations located in the vicinity of the WWTP. The flow-meter data is managed by a SCADA system (PC WIN2) which was also integrated into the DSS. Measured data is managed by Microsoft database SQL Server.

The DSS presents three main components: (i) an information component that includes all the monitoring data, infrastructure inventory, and relevant operational data; (ii) hydrological, hydrodynamic and water quality model, integrating Ave River sub-basins, main rivers and the main sewer network; and (iii) a system that will be responsible for the analysis and processing of data to be used in the operational management of the system. The model is operated using the Delft-Fews platform. Its calibration was based on meteorological, hydrological and river discharge data obtained from SNIRH (National water resources information system) and TRATAVE monitoring network. Forecasting capabilities are implemented to anticipate intense rainy days, therefore improving the performance of the company by taking the most adequate measures to deal with undesirable infiltrated water volumes that are transported to the WWTP. Forecasts are based on the implemented hydrological models and on precipitation forecasts from atmospheric models developed by NOAA (National Oceanic \& Atmospheric Administration) and Meteogalicia (Spanish water resources databases). 


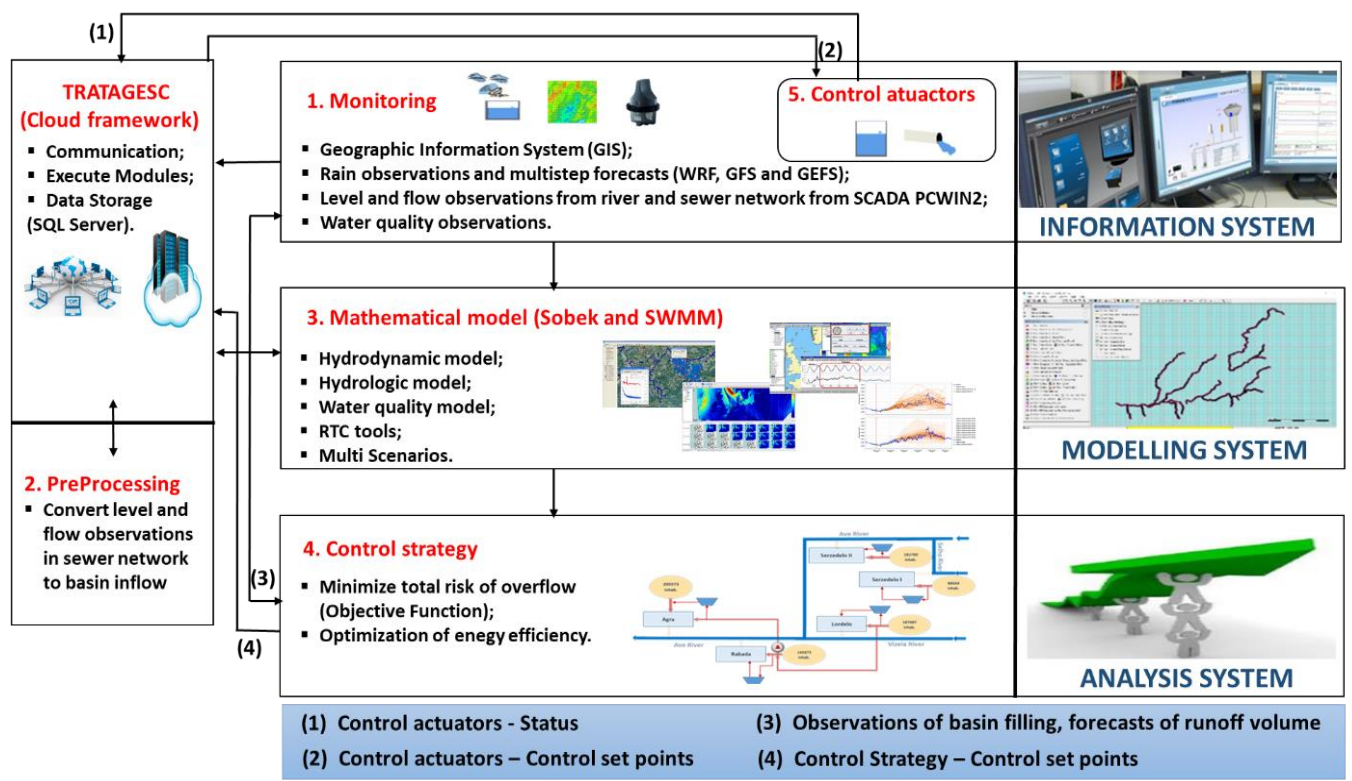

Figure 2 DSS main components.

The actual version of the implemented system already allowed for the identification of several unlicensed sewer network connections, mainly of industrial wastewaters, and the analysis of the corresponding historical databases allow for the definition of temporal discharge patterns for dry weather conditions. These patterns are used in the estimation of infiltrated volumes for wet periods, by subtracting the measured discharges to the expected discharge for dry weather conditions.

The objective of this work is to compare the observed meteorological data through the data available in the stations of the SNIRH network, rain gauges located in four points of the intercourse network under study, data synthetically generated through atmospheric models developed by NOAA, namely GFS and GEFS and data from the Meteogalicia radar and WRF model to the Ave river basin.

Delft-FEWS platform was used to implement a river and drainage wastewater network forecasts system to the NW region of Portugal. Historic hydro-meteorological data series from the SNIRH (Figure 3 a)), meteorological data from Meteogalicia (Figure 3 b)), radar data and results from atmospheric model predictions were used as data-feeds of the system. Hydrological and hydrodynamic forecasts are performed based on the following deterministic precipitation predictions: NOAA's Global Forecast System (GFS, Figure 3c)), MeteoGalicia's Weather Research and Forecasting (WRF, Figure 3d)) and NOAA's Global Ensemble Forecast System (GEFS). The first (GFS) model presents precipitation forecasts for ten-days horizons with a spatial resolution of $0.1^{\circ}$ lon $\mathrm{x} 0.1^{\circ}$ lat at six-hour intervals. The second (WRF), the forecast horizon is four days with a spatial resolution of $4 \mathrm{~km} \mathrm{x} 4 \mathrm{~km}$, with hourly resolution for a region that covers Galicia and Northern Portugal and the third (GEFS) present 21 ensemble members for sixteen days forecast horizons with a spatial resolution of $27 \mathrm{~km} \mathrm{x}$ $27 \mathrm{~km}$.

The hydrodynamic and water quality model of Ave River basin and sewerage network are presented (Figure $3 \mathrm{j}$ ) and some examples of data generation (Figure $3 \mathrm{f}-\mathrm{i}$ )).

In figure 3 , the main data sources used in the construction of DSS are presented. 

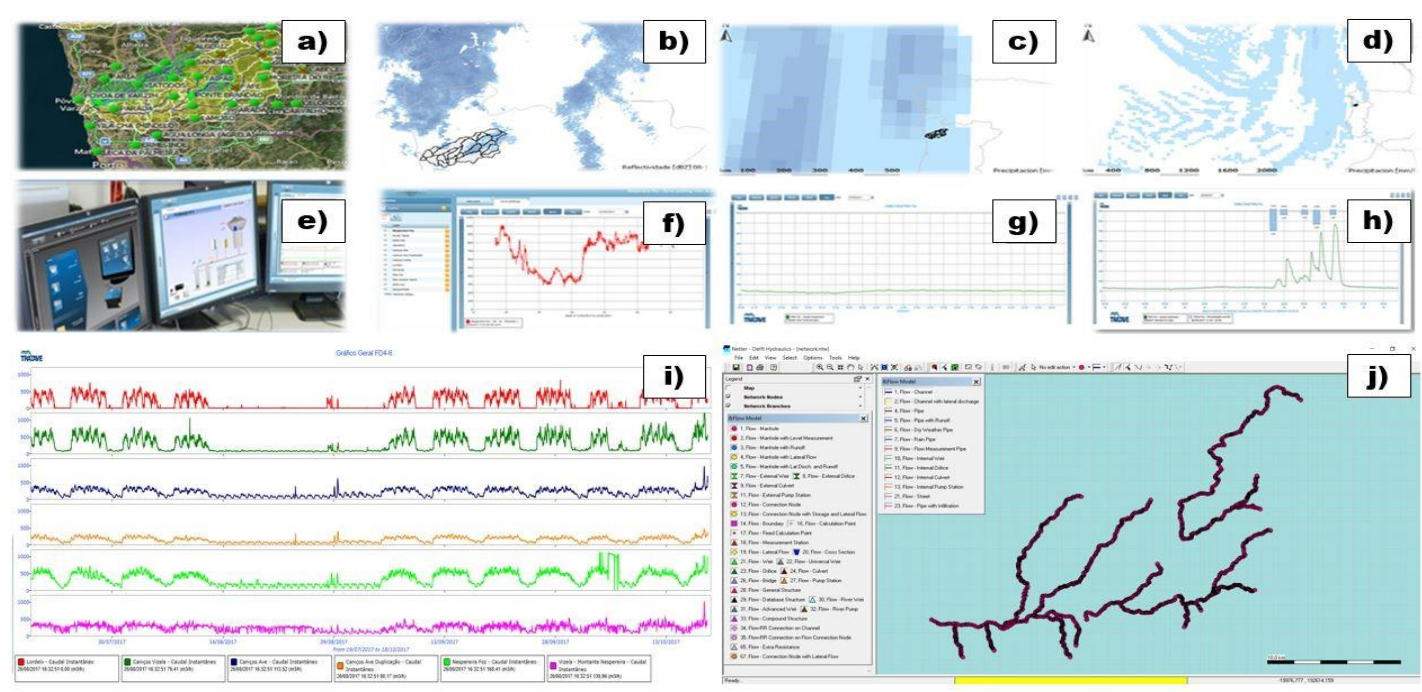

Figure 3 Data sources used in the construction of the DSS platform: a) SNIRH weather station, b) Meteogalicia radar reflectivity records, c) NOAA GFS model forecasts, d) Meteogalicia WRF model forecasts, e) An image of SCADA PCWIN2 for flow monitoring (river and sewerage), f-i) Example of data generation through flow monitoring system and g) Hydrodynamic and water quality model of the Ave River basin and sewerage network.

\section{Results and Discussion}

Considering the existing hourly measured precipitation and flow data for the period between $1 / 10 / 2015$ to $30 / 8 / 2017$, in one of the main sewers, computing the daily average discharges for dry and wet periods was possible. As seen in Figure 4 (left), wastewaters discharges transported to the WWTP double their value during wet days. This is quite problematic since all the WWTP were designed to receive domestic and industrial effluents with residual volumes of infiltrated storm waters. The typical hourly flows during dry weather conditions were obtained for this main sewer (Figure 4 - right). The importance of the received industrial effluents is very clear from the obtained typical flow patterns for the different days of the week: an almost constant value flows on Sundays. This value rises on Monday's beginning early in the morning. Tuesdays, Wednesdays, Thursdays, and Fridays, present an hourly flow variation with identical patterns, but an increase in average values. On Saturdays, the flow continuously decreases along the day.
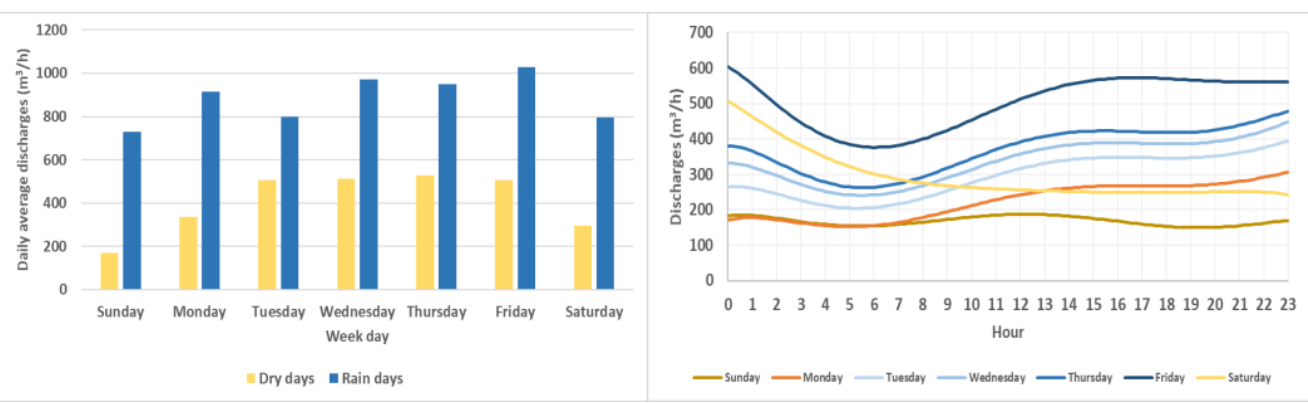

Figure 4 Typical daily average discharges during wet and dry periods (left) and hourly discharge flow patterns for dry periods (right). 
The correlation between hourly measured wastewater discharges and precipitations is not clear when plotted in the same graph (Figure 5 - left). However, this correlation is evident if the cumulative values of precipitation (Taipas and Serzedelo precipitation gauge stations) and infiltrated discharges (Ave sewer) are considered (coefficients of determination for these variables of the order of 0,90 ), which can be observed in Figure 5 (right) for two intense rain events that took place between 01/01/16 and $15 / 02 / 16$.
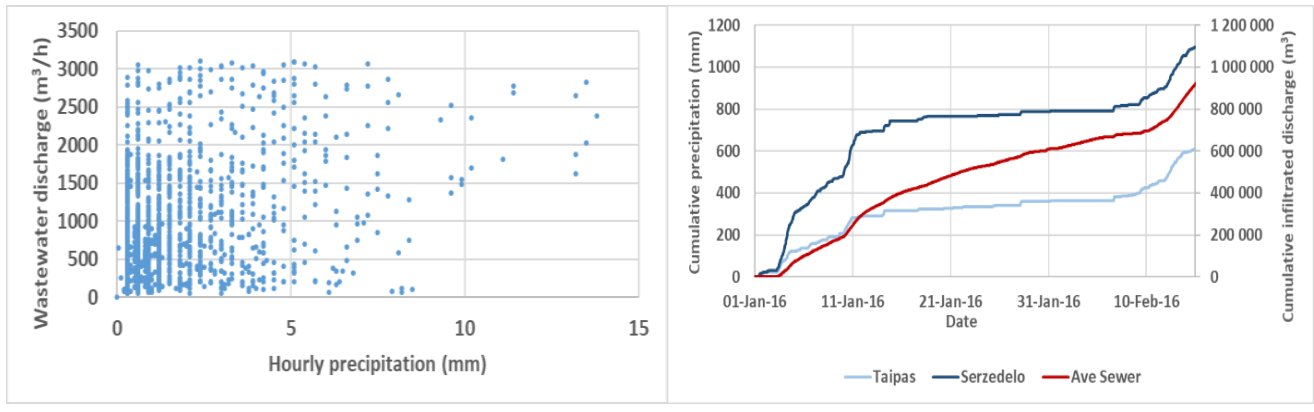

Figure 5 Hourly wastewater discharges versus precipitation measurements (left) and cumulative precipitation and infiltrated discharges during two intense rain events (right).

The infiltration starts at the very beginning of the rain event, perhaps by entering through shaft manholes. When the first precipitation event ends, the infiltrated flow continues to rise, which can be associated with infiltrations along pipe joints in a process that can be associated with the aquifer base flow. From these results, arise the necessity of properly managing the infiltrated flows during rain events that involve considerable volumes of water. This can be achieved by creating temporary storage wastewater reservoirs and/or distributing the incoming flows to the different WWTP (Figure 6). Ongoing research is focused on the development of advanced model predictive control (MPC) strategies to support operational management decisions on this complex system. This support includes the forecasting of precipitations and consequently the infiltrated flows, the installed storage and treatment capacity, and, finally, the impacts of different transport/treatment alternatives of the receiving waters, assessed by the river water quality model.

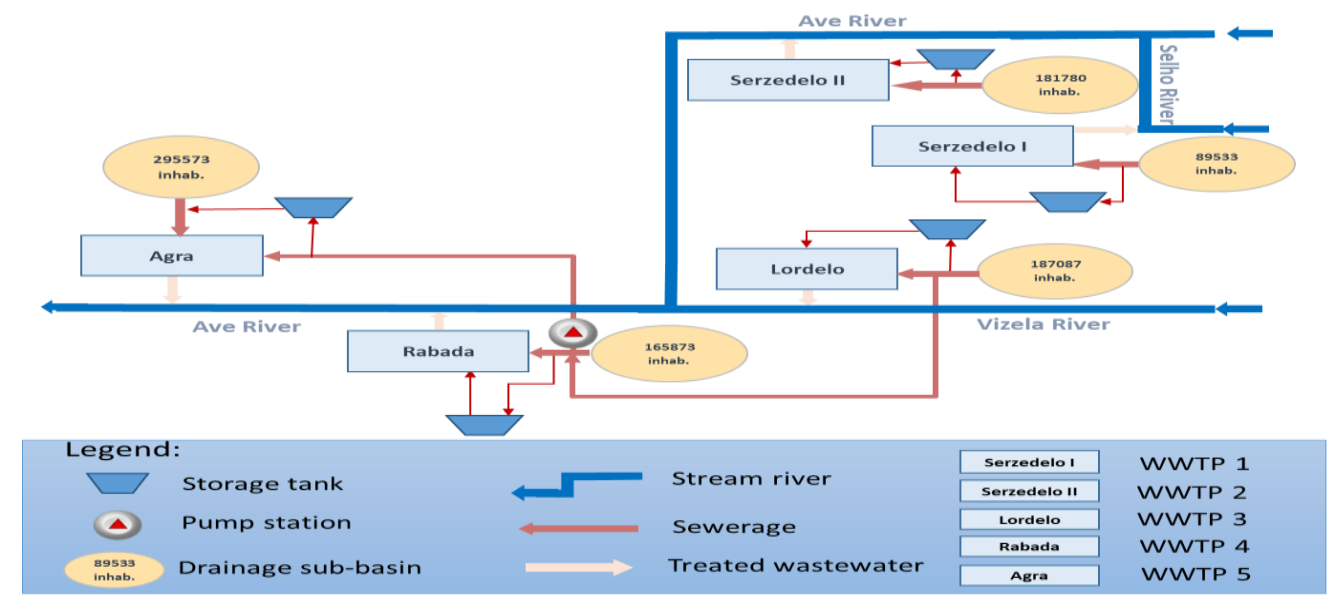

Figure 5 Conceptual scheme for operational management of TRATAVE transport and wastewater treatment facilities to improve management of infiltrated flows during wet periods. 


\section{Conclusions}

A relatively complex transport and treatment system is being used as a living lab to support research on proper operational control techniques to deal with infiltration of stormwater in sewer networks. A DSS is being implemented with the use of a specific monitoring network, advanced hydroinformatic tools, including the Delft-FEWS platform and integrated hydrological, hydrodynamics and water quality models. Infiltration water volumes can double the normal wastewater discharges typical of dry periods. Cumulative precipitation presents a strong correlation with estimated infiltrated water volumes and will be used to assess different operational management strategies to properly transport, store and treat collected wastewaters during wet periods.

The decision support tool presented for the Ave River basin constitutes a robust and efficient technological platform to support water management at a river basin scale. The obtained results show that this new tool will be extremely effective and important to achieve the objectives of water management at river basin scale. In upcoming years, the use of this developed tool in all problem solving constitutes a major challenge for its evaluation. Furthermore, once water authorities decide to use this kind of management tool, an improvement of their analysis capabilities will certainly be seen, as well as a strengthening in their technological skill for the adoption of more sustainable water management policies. This is especially suited for developing big projects since it facilitates collaborative studies on one common platform and, therefore, the modeling results become much more transparent for all project partners.

\section{Acknowledgements}

The authors thank TRATAVE for the financial, human and technological resources given to this study, which contributed to the development of innovative and useful tools to the decision support in planning and managing of water resources in Portuguese basins.

\section{References}

Butler, D., \& Schutze., M. (2005). Integrating simulation models with a view to optimal control of urban wastewater systems . Environmental Modelling \& Software, 20(4), 415-426.

Fletcher, T., Andrieu, H., \& Hamel., P. (2013). Understanding, management and modelling of urban hydrology and its consequences for receiving waters. Advances in Water Resources, 51, 261279.

Joseph-Duran, B., Carlos, O.-M., \& Cembrano, G. (2014). Hybrid modeling and receding horizon control of sewer networks. Water Resources Research, 50, 8497-8514.

Lowe, R., Vezzaro, L., Steen, P., \& Grum., M. (2016). Probablistic runoff volume forecasting in riskbased optimization for RTC of urban drainage systems. Environmental Modelling Software, $80,143-158$.

Pereira, A., Pinho, J. L., \& Faria., R. (2016). Monitoring network of TRATAVE S. A. sewer system and treatment infrastructures. $17^{\circ}$ ENASB - Encontro Nacional de Engenharia Sanitária $e$ Ambiental (pp. 1-8). Guimarães, Portugal: Associação Portuguesa de Engenharia Sanitária e Ambiental (APESB).

Pinho, J. L., \& Vieira., J. M. (2014). A web-based hydroinformatic platform for water quality modelling in a river basin. 11th International Conference on Hydroinformatics (pp. 1-8). New York, USA: CUNY Academic Works. 